lymphomata arise from B cells, which in turn develop in the centres of the lymphoid follicles found typically at the periphery of the lymph node. Lukes and Collins trace a transformation of small lymphocytes in the follicular centre through a possible plasmacytoid stage to a phase of nuclear cleavage which culminates in the development of a non-cleaved cell with much pyroninophilic cytoplasm and a number of nucleoli. These follicular centre cell (F.C.C.) types are classified as small cleaved, large cleaved, small non-cleaved, and large non-cleaved. The last resembles a fully transformed lymphocyte, and is called an immunoblast when it leaves the follicles and enters the interfollicular tissue.

On the basis of this development of the B cell, seven types of lymphomata can be recognized: chronic lymphatic leukaemia from the small lymphocyte, the closely related macroglobulinaemia described by Waldenström from the plasmacytoid variant of the small lymphocyte, lymphomata from each of the four types of F.C.C., of which the cleaved cells show the greater tendency to nodular dispositions and the better prognosis, and finally the immunoblastic sarcoma, which closely resembles a lymphoma arising from the large non-cleaved cell. It may occur as a complication of chronic abnormal immune states, in Sjögren's syndrome, in patients on immunosuppressive therapy, or in the aged. Histiocytic lymphomata are rare, for nearly all the cells that were previously called histiocytes (or reticular cells) are now shown to be transformed lymphocytes.

This classification, though complicated, throws much light on the histogenesis of the lymphomata, for it combines functional studies with the purely cytological description that was the basis of previous classifications. It elucidates the nodular and diffuse disposition of lymphoma cells, and also puts into clearer perspective the condition previously called reticulum-cell sarcoma.

1 Rappaport, H., Winter, W. J., and Hicks, E. B., Cancer, 1956, 9, 792.

2 Rappaport, H., Tumours of the Haematopoietic System, p. 91. Washington, D.C.: Armed Forces Institute of Pathology, 1966.

${ }^{3}$ Lukes, R. J., Butler, J. J., and Hicks, E. B., Cancer (Philadelphia), 1966, 19, 317.

${ }^{4}$ Lukes, R. J., Cancer Research, 1966, 26, 1311.

5 Symposium on Non-Hodgkin's Lymphomata, British fournal of Cancer, 1975, 31, Supplement No. II.

${ }^{6}$ Lukes, R. J., and Collins, R. D., British Fournal of Cancer, 1975, 31, Supplement No. II, 1.

\section{Diabetic Nephropathy}

Diabetic nephropathy can be a dangerous disorder with a variable and unpredictable course. However, since new treatments by dialysis and transplantation are still being developed, more detailed knowledge of the natural history of the disorder is needed.

Proteinuria is the clinical hallmark of diabetic nephropathy and the simplest guide to its prognosis. It becomes increasingly common as duration of diabetes increases, ${ }^{1}$ and in young diabetics most deaths occur in patients with proteinuria. ${ }^{2}$ It has been estimated that $77 \%$ of young patients will be dead 10 years after the appearance of proteinuria. ${ }^{3}$ Prognosis is worst in those with heavy proteinuria, ${ }^{4}$ and the nephrotic syndrome therefore represents a very advanced stage of the disease. ${ }^{5}$ Patients with diabetic nephropathy have a greatly increased risk of atheroma, and this is intensified by both increasing age and duration of diabetes. ${ }^{6}$ Death is mainly due to uraemia in younger patients and to myocardial infarction in the older ones. ${ }^{7}$

Many renal biopsy studies in diabetics have attempted to evaluate the disease's severity, and sometimes serial biopsies have been used to follow its course. ${ }^{489}$ There is some correlation between histological changes, proteinuria, and renal function, especially with diffuse glomerulosclerosis. ${ }^{8}$ The most recent and extensive study of serial biopsy specimens comes from Japan, ${ }^{10}$ where the results of 23 renal biopsies were reviewed at further biopsy (or in two cases at necropsy) two to eight years later. Progression of the renal lesion was observed in 13 , but there had been no change in 10 . It is generally agreed that lesions once established never regress, but-as in the case of retinopathy-they do not necessarily progress. Advanced lesions seem to deteriorate more rapidly than early ones, and this is in keeping with clinical observations. The course of the disease is not reliably predictable from histological appearances, and occasionally even the more severe lesions may not change over several years. Nodular lesions and the fibrinoid cap both forecast a bad outlook, but even then exceptions do occur. It is, therefore, rarely helpful to undertake a renal biopsy in these patients unless the diagnosis is in serious doubt.

The factors causing diabetic nephropathy or those determining its progression are still unknown. There is no convincing evidence that poor control causes diabetic nephropathy or in any way alters its course. The recent Japanese biopsy study attempted to relate control to the progression of biopsy appearances, but in fact it showed how difficult interpretation can be, since the different groups of patients were not really comparable. Experimentally there is evidence that diabetic glomerulosclerosis may actually regress if the kidneys are transplanted into non-diabetic animals, ${ }^{11}$ and after islet transplantation, ${ }^{12}$ but such studies are a long way from reality. On the other hand there is as yet no evidence that normal kidneys transplanted into diabetics develop specific changes of diabetic nephropathy, ${ }^{13}$ but follow-up periods have been relatively short.

Most physicians believe that these patients should receive the best possible diabetic control-often difficult in renal failure-but it remains disappointing that there is no scientific evidence of a reward for doing so. Control of hypertension, which occurs late in the course of the disease, is obviously desirable, but the effect on prognosis is unknown. Hyperlipidaemia is common in diabetic nephropathy patients ${ }^{8}$ and no doubt contributes to the atheroma to which they are particularly susceptible, but at present one cannot be sure whether its control is beneficial. Growth hormone excess ${ }^{14}$ is often blamed for diabetic complications, but again this is controversial and there is no good evidence that its control improves diabetic nephropathy. Hypophysectomy actually causes glomerular filtration to fall. ${ }^{15}$ Somatostatin is still an experimental tool which decreases growth hormone secretion, ${ }^{16}$ and it will be many years before its clinical effects can be evaluated.

Once renal failure is established in diabetic nephropathy a downhill course is certain and survival is usually less than two years. ${ }^{3}$ Whether at this stage either the quality of life or its duration can be improved is still controversial. Chronic dialysis patients run a stormy course, and survival figures are poor when compared to non-diabetics. ${ }^{17} 18$ Renal transplantation may hold out better prospects, ${ }^{13}$ but even in these patients cardiovascular disease takes a heavy toll. The trend to perform transplantation at an earlier stage of the disease makes it more important than ever to understand the natural course of the disease and to try to discover any methods by which to influence it. 
1 White, P., Diabetes, 1956, 5, 445.

${ }^{2}$ Deckert, T., and Poulsen, J. E., Acta medica Scandinavica, 1968, 183, 351.

3 Knowles, H. C., Kidney International, 1974, 6, supl no. 1, 52.

4 Watkins, P. J., et al., Quarterly fournal of Medicine, 1972, 41, 437.

${ }^{5}$ Sarre, H., et al., Deutsche Medizinische Wochenschrift, 1971, 96, 225.

6 Knowles, H. C., Transactions of the Association. of American Physicians, $1971,84,95$.

7 Marks, H. H., American Fournal of Public Health, 1965, 55, 416.

8 Gellman, D. D., et al., Medicine (Baltimore), 1959, 38, 321.

9 Thomsen, A. C., The Kidney in Diabetes Mellitus. Munksgaard, Copenhagen, 1965.

10 Takazakura, E., et al., Diabetes, 1975, 24, 1.

11 Lee, C. C., et al., Journal of Experimental Medicine, 1974, 139, 793.

12 Mauer, S. M., et al., Diabetes, 1975, 24, 280.

13 Kjellstrand, C. M., et al., Kidney International, 1974, 6, suppl. no. 1, 815.

14 Johansen, K., and Hansen, A. P., British Medical fournal, 1969, 2, 356.

15 Teuscher, A., et al., Diabetes, 1970, 19, 502.

${ }^{16}$ Hall, R., et al., Lancet, 1973, 2, 581.

17 White, N., et al., Nephron, 1973, 11, 261.

18 Shapiro, F. L., et al., Kidney International, 1974, 6, suppl. no. 1, 58.

\section{Doctors as Managers}

Reorganization was intended to bring clinicians into the management of the N.H.S.- they were expected" to "help to determine priorities among competing or conflicting claims and recommend and put into practice new ways of making the most of resources available." Inevitably some conflicts might have been expected between these clinicians and the full-time professional administrators, but the experience of the first year as described at our Chichester conference (p. 54) did not suggest that this has been a major problem.

The real gulf seems to have been between the district management teams-six people (a consultant, a G.P., a community physician, a nurse, a finance officer, and an administrator) meeting regularly to cope with practical problems, and necessarily familiar with the new language ${ }^{2}$-and the area health authorities, who might meet for only two hours a month. The full-time officers of the area team have had the uneasy task of trying to bridge this gulf.

In theory, district teams were expected to reach their decisions by consensus and refer matters on which they failed to agree to the area; in practice they seem to have decided that lack of decision is tantamount to defeat, and differences of opinion have been kept within the family and concealed from the area authority. As a result, decisions on controversial issues have been postponed rather than referred elsewhere. Quite deliberately, specific guidance was not given in the management "grey book" on the exact division of function between the district and area teams, authorities, and committees, and the first year has seen a lot of jockeying for power and position. Districts have found they can starve areas of basic data, but conversely the areas have been able to veto projects and apply financial pressures. The single-district areas have been noticeably free from these conflicts.

Yet during their first year these infant administrative units have had to cope with unprecedented problems: industrial action by N.H.S. employees at all levels and a financial freeze. In coping with these difficulties the clinician-managers have learnt that they cannot act simply as representatives of their own sectional interests: the service has had to be run, and unpleasant and unpopular decisions have been made and accepted by the professional groups affected. The financial problems have been specially galling in many districts because of anomalies and inconsistencies. Most districts have had very little money: a few-because of some quirk based on preorganization finances-have found themselves with no serious shortage at any stage. What money there has been has arrived in fits and starts, so that after an apparent total freeze unexpected revenue suddenly arrived towards the end of the year. District management teams who have survived the first 12 months may be forgiven for believing that if they could cope with such a year they can cope with anything.

The full-time medical administrators have also had a hard time adjusting to their new roles. Most of the new community physicians came from the public health service, and some have succumbed to the temptation of concentrating their efforts on those aspects of their new jobs for which their old training fitted them, especially the clinical work. In fact the coordinating role of the community physician still has a big question mark hanging over it-speakers at the conference asked whether this role would have been incorporated into the reorganized structure had a new function not had to be found for former public health medical officers. Meanwhile the new local authorities no longer have medical advice on tap, and environmental health may be neglected, including important contemporary problems such as pollution, health and housing, and noise. It is even rumoured that some local authorities have been considering appointing medical officers because they are not content with the arrangement whereby they have to ask the area health authority each time they need a medical opinion.

As yet it is far too early to pass any judgement on the workings of the new Service. Virtually no planning has been possible, partly because the essential data have yet to be collected, and partly because the economic future is so uncertain that budgeting forecasts are guesswork. Harsh choices will have to be made in the coming months, however, and these will be the real challenge to the management theorists. In the past only too often a draconic decision made locally has raised a howl of protest from those affected and has been overruled by the Department of Health-without providing any more money to resolve the consequences. We are facing a future in which real cuts will have to be made rather than simply delaying expansion or rebuilding, and it is when the money runs out that consultative democracy is really needed.

The pioneers who have learnt to operate the district teams and the medical committees are still clinicians most of the week, and unfortunately many have found that the demands made by committees on their time and energy have been exhausting and damaging to the rest of their lives. At the end of their second and third years of struggle many of these amateur managers may want to return to full-time medicine. How long will it take their successors to learn the language and establish trusting relations with the professionals? One crucial lesson of the first year has been that management requires skills that take time to learn. Doctors are not given these skills as a concealed bonus with their medical degrees: their acquisition requires patience and application. Are there enough clinicians with the interest and enthusiasm and time to make the necessary effort?

\footnotetext{
${ }^{1}$ Department of Health and Social Security, Management Arrangements for the Reorganized Health Service. London, H.M.S.O., 1972.
} 2 British Medical fournal, 1975, 2, 705. 